doi: $10.4248 / \operatorname{IJOS} 09061$

\title{
Relationship of Periodontal Status and Dental Caries Status with Oral Health Knowledge, Attitude and Behavior among Professional Students in India
}

\author{
Archana J. Sharda*, Srinath Shetty
}

Department of Preventive and Community Dentistry, Pacific Dental College \& Hospital, Debari, Rajasthan, India

\begin{abstract}
Archana J. Sharda, Srinath Shetty. Relationship of Periodontal Status and Dental Caries Status with Oral Health Knowledge, Attitude and Behavior among Professional Students in India. International Journal of Oral Science, 1(4): 196-206, 2009

Aim To find the relationship of periodontal status and dental caries status with oral health knowledge, attitude, behavior, among professional students in India.

Methodology In a cross sectional study, a total of 825 students (males: 577, females: 248) from six professions were surveyed using a self administered structured questionnaire including 41 multiple choice questions and the WHO Oral Health Assessment Form (1997). The data was analyzed using the SPSS version 13.0 to perform the Student's $t$-test, ANOVA test, Scheffe's test and Chi-square test, linear regression analysis.
\end{abstract}

Results The mean percentage scores of the students for knowledge were $53.25 \pm 15.05$; for attitude $74.97 \pm 20.48$; and for behavior $59.09 \pm 18.77$. The percentage of students with calculus score was found to be significantly high $(43.8 \%)$. The percentage of professional students with DMFT $>4$ was $14.1 \%$ and the percentage of students with decayed teeth was $46.2 \%$. The regression analysis showed that the oral health behavior of the students was dependent on the attitude $(P<0.001)$, but showed no significant linear relation with the knowledge. Also, that the mean DMFT score was dependent on the oral health behavior $(P<0.05)$, but showed no significant relationship with the knowledge and attitude of the students. The periodontal status was independent on the knowledge, but showed a significant relationship with attitude and behavior of the students.

Conclusion A positive attitude and adherence to good oral hygiene behaviors is associated with better oral health.

Keywords oral health knowledge, attitude, oral health behavior, professional students

Received Jul. 31, 2009; Revision accepted Oct. 27, 2009

\section{Introduction}

Health is a valuable asset not only for an individual, but also for the social system. A nation may progress more rapidly when the population are healthier and lead a productive life. "Public health is the coalition of professions united by their shared mission" (Institute of Medicine Committee for the study of the future public health, Division of Health Care Services, 1988). The phrase "coalition of professions" stresses that the achievement of better public health requires more than the participation of the various health professions: public health individuals and groups band together to achieve a common goal (Block et al., 2003).

Oral health is now recognized as equally important in relation to general health. Various factors like nutritional status, tobacco smoking, alcohol, hygiene, stress, etc. are linked to a wide range of oral diseases forming the fundamental basis of the common risk factor approach (WHO, 2000) to prevent the oral diseases (Sheiham et al., 2000). Among these, oral hygiene is the most significant 
factor in terms of prevention of oral diseases. The oral health concern of an individual is dependent on the attitude of a person. These attitudes naturally reflect their own experiences, cultural perceptions, familial beliefs, and other life situations and strongly influence the oral health behavior (Friedman et al., 1976; Wright, 1982; McCaul et al., 1985; Chen 1986).

The broad categories of factors that may influence individual and community health behavior include: knowledge, beliefs, values, attitudes, skills, finance, materials, time, and the influence of family members, friends, co-workers, opinion leaders, and even health workers themselves (Park, 2005). Those who have assimilated the knowledge and feel a sense of personal control over their oral health are more likely to adopt self-care behavior (Freeman et al., 1993). The goal of oral health promotion is - knowledge to be shared with members outside the dental profession.

Among common oral diseases, caries and periodontal diseases are the two foremost oral pathologies that remain widely prevalent and affect all populations throughout the life span (Barmes, 1999). The risk behaviors for dental caries and periodontal disease include frequent intake of sugary foods and drinks, irregular tooth brushing, smoking, alcohol consumption and irregular dental attendance (Levine et al., 2001). These risk behaviors could be habitual from early childhood or be initiated during adolescence related to an emerging autonomy from parental influence. Indeed, adolescence is a crucial period of transition (Berndt, 1982; Hopkins, 1994; Maxwell, 2002) with personal responsibility for preventing dental disease beginning at this age and determining future oral health (Honkala, 1995; Peterson, 1988). Therefore, assessing the oral health awareness, periodontal status and dental caries status of young adult becomes essential. One group from the population that could be easily used for this purpose is the professional college students.

Several recent studies reveal the oral health attitudes and behaviors of young adult and the relation between their attitudes and behaviors and their dental and oral status (Kawamura et al., 1993; Holanka, 1995). Oliveria et al. reported that children without adequate oral health knowledge are twice as likely to have caries than those with adequate knowledge (Oliveria et al., 2000).

To date, information is limited regarding the public's knowledge and attitude about oral diseases and their prevention. With a higher education background the concept of prevention and well-being could be more easily understood by people, irrespective of their course of study. So the present study was conducted to assess the oral health knowledge, attitude, behavior, the periodontal status and dental caries status of professional college students.

\section{Materials and methods}

\section{Sampling design}

An epidemiological survey was conducted from December 2007 to February 2008. A staged simple random sampling method was used to select six different professional colleges (Management, Engineering, Physiotherapy, Pharmacy, Homeopathy and Ayurveda) in Udaipur City. From the total number of students pursuing the undergraduate course of studies in each of the selected colleges, all the available students who agreed to participate in the survey were selected, which gave a sample size of 825 subjects (Table 1). The mean age of all the students (in years) was $19.38 \pm 1.57$.

\section{Official permission}

Before the start of the survey official permission was obtained from the corresponding authorities and an ethical approval was obtained from the ethical committee.

\section{Survey proforma}

The survey proforma was prepared with the help of a self administered structured questionnaire written in English to assess the oral health knowledge, attitude and behavior of the students and WHO Oral Health Assessment Form (1997) to assess the dental caries status and periodontal status of the students.

The questionnaire was validated through a pilot survey, included 41 items (One question on source of health information, twenty questions on oral 
Table 1 Distribution of the study subjects by course of study and gender and percentage of students that participated from total number enrolled in each professional college (sample size)

\begin{tabular}{|c|c|c|c|c|c|c|}
\hline \multirow{3}{*}{ Category } & \multirow{3}{*}{$\begin{array}{l}\text { Course } \\
\text { of study }\end{array}$} & \multicolumn{4}{|c|}{ No. of students } & \multirow{3}{*}{$\begin{array}{c}\text { Percentage } \\
\text { of total no. } \\
\text { participated } \\
\quad / \%\end{array}$} \\
\hline & & \multirow{2}{*}{$\begin{array}{l}\text { Total no. enrolled } \\
\text { for the course }\end{array}$} & \multicolumn{3}{|c|}{ No. participated in the survey } & \\
\hline & & & $\mathrm{M}(\%)$ & $F(\%)$ & Total $(\%)$ & \\
\hline \multirow[t]{2}{*}{ A } & 1 & 300 & $110(82.7)$ & $23(17.3)$ & $133(100)$ & 44.33 \\
\hline & 2 & 400 & $101(71.6)$ & $40(28.4)$ & $141(100)$ & 35.25 \\
\hline \multirow[t]{2}{*}{ B } & 3 & 200 & $68(48.9)$ & $71(51.1)$ & $139(100)$ & 69.50 \\
\hline & 4 & 240 & $112(80.0)$ & $28(20.0)$ & $140(100)$ & 58.33 \\
\hline \multirow[t]{3}{*}{ C } & 5 & 200 & $100(74.6)$ & $34(25.4)$ & $134(100)$ & 67.00 \\
\hline & 6 & 240 & $86(62.3)$ & $52(37.7)$ & $138(100)$ & 57.50 \\
\hline & Total & 1,580 & 577 (69.9) & $248(30.1)$ & $825(100)$ & 52.22 \\
\hline
\end{tabular}

A: Non-Medical, B: Para-Medical, C: Medical. 1: Management, 2: Engineering, 3: Physiotherapy, 4: Pharmacy, 5: Homeopathy, 6: Ayurveda. M: Males, F: Females.

health knowledge, six questions on oral health attitude and fourteen questions on oral health behavior) designed to evaluate the oral health knowledge, attitude and behavior of the students (Zhu et al., 2003).

The dental caries status was recorded from the dentition status and treatment needs as described by WHO (1997). The periodontal status was recorded by using the CPI scores as described by WHO (1997).

\section{Methodology}

All the students in the selected professional colleges were invited to participate in the survey. The purpose of the study was informed and explained to the students. Those who voluntarily agreed to participate in the survey and gave a written consent for the same, were asked to respond to each item according to the response format provided in the questionnaire. The students took an average of 15 minutes to complete the procedure. Anonymity of the respondents was assured.

The oral examination of the students was conducted simultaneously under natural light. The examination of dental caries and periodontal status was made using the Community Periodontal Index probe and a mouth mirror. On an average it took 5 to 6 minutes to complete the oral examination of each student. All the instruments were autoclaved daily.

\section{Statistical analysis}

Scoring was done and the data was analyzed using the Statistical Package for Social Sciences version 13.0 software. The individual scores were summed up to yield a total score. Descriptive statistics were obtained and mean percentage scores, standard deviation, and frequency distribution were calculated for the oral health knowledge attitude and behavior items.

The periodontal index scores and dental caries scores were computed according to WHO recommendations (WHO, 1997). The prevalence proportion rates and mean values and standard deviation were calculated for the purpose of analysis.

The Student's $t$-test, ANOVA test and Scheffe's test were applied for the statistical evaluation of means and Chi-square test was used for comparisons of proportions. The linear regression analysis was used to find the relation of oral health behavior with the knowledge and attitude and to find whether the dental caries status is dependent on the oral health knowledge, attitude and oral health behavior of the students. Level of significance was set at 0.05 and 0.001 . 


\section{Results}

\section{Sample size}

A total of 825 students (males: 577, females: 248) participated in the survey. For the purpose of discussion and comparison all the different professions were categorized into three different categories (depending on their course of study) such as Non-Medical, Para-Medical and Medical. The percentage of students participated from each professional college (sample size) and the distribution of the study subjects by course of study and gender is shown in Table 1.

\section{Source of health information}

The distribution of students according to the source of health information is given in Table 2 .

Table 2 Percentage of students with different source of health information

\begin{tabular}{lc}
\hline Source of health information & Percentage /\% \\
\hline Dental clinic & 12.4 \\
Physician's office & 17.5 \\
Family members & 15.8 \\
Friends/Neighbours & 6.7 \\
Radio/Television & 15.6 \\
News paper & 11.6 \\
Magazine/Books & 20.5 \\
\hline
\end{tabular}

\section{Oral health knowledge, attitude and behavior}

As shown in Table 3, the knowledge scores were significantly higher for the students in Medical category $(55.42 \pm 13.75)$ compared to the Non-Medical category $(50.73 \pm 15.96)$. Whereas, there was no statistically significant difference in the knowledge scores between the Medical and Para-Medical categories. Overall, the knowledge scores were highest for the students in the Medical category.

The attitude scores were significantly lower for the Non-Medical category $(69.04 \pm 22.54)$ compared to the other two categories. There was no statistically significant difference between the attitude scores of the students in the Medical and ParaMedical categories. Para-Medical category studends
Table 3 Assessment and comparison of mean percentage knowledge, attitude and behavior scores among the professional students

\begin{tabular}{|c|c|c|c|c|c|}
\hline & & No. & Mean & SD & $P$ \\
\hline \multirow[t]{4}{*}{ KS } & $A$ & 274 & $50.73(\mathrm{a})$ & 15.96 & $0.001^{* *}$ \\
\hline & B & 279 & 53.62 & 15.02 & \\
\hline & $\mathrm{C}$ & 272 & $55.42(b)$ & 13.75 & \\
\hline & Total & 825 & 53.25 & 15.05 & \\
\hline \multirow[t]{4}{*}{ AS } & A & 274 & $69.04(a)$ & 22.54 & $0.000^{* *}$ \\
\hline & B & 279 & 79.69 (b) & 19.53 & \\
\hline & C & 272 & 76.10 (b) & 17.68 & \\
\hline & Total & 825 & 74.97 & 20.48 & \\
\hline \multirow[t]{4}{*}{ BS } & $A$ & 274 & $55.16(a)$ & 19.06 & $0.000^{* *}$ \\
\hline & B & 279 & $60.78(b)$ & 18.80 & \\
\hline & $\mathrm{C}$ & 272 & $61.32(b)$ & 17.86 & \\
\hline & Total & 825 & 59.09 & 18.77 & \\
\hline
\end{tabular}

A: Non-Medical, B: Para-Medical, C: Medical. KS: Knowledge score, AS: Attitude score, BS: Behavior score. Test used ANOVA and Scheffe test. a and b: Means with different alphabets differ significantly with $P<0.05$. **: $P \leq 0.001$.

showed highest attitude scores $(79.69 \pm 19.53)$.

The behavior scores were significantly lower for the students in Non-Medical category $(55.16 \pm 19.06)$ compared with the students in the Para-Medical and the Medical categories. Though there was no statistically significant difference in the behavior scores of the students in the Medical and NonMedical categories, the scores were highest for the Medical category students (61.32 \pm 17.86$)$.

The knowledge, attitude and behavior scores were significantly higher for female students compared to their male colleagues, as shown in table 6 .

\section{Periodontal status}

Table 4 shows that the mean number of sextants with healthy periodontium did not show a statistically significant difference in Non-Medical, Paramedical and Medical categories.

The mean number of sextants with bleeding on probing was significantly higher for the NonMedical category $(1.48 \pm 1.61)$ compared to the Para-Medical (1.17 \pm 1.45$)$ and Medical categories $(1.01 \pm 1.28)$. No statistically significant difference was found in the mean number of sextants with bleeding on probing between the Para-Medical and Medical categories. 
Table 4 Assessment and comparison of mean number of sextants with different CPI scores among the professional students

\begin{tabular}{llllcc}
\hline & & No. & Mean & SD & $P$ \\
\hline S0 & A & 274 & 3.69 & 2.17 & 0.251 \\
& B & 279 & 3.99 & 2.19 & \\
& C & 272 & 3.76 & 2.27 & \\
& Total & 825 & 3.81 & 2.21 & \\
S1 & A & 274 & $1.48(\mathrm{a})$ & 1.61 & $0.001^{\text {** }}$ \\
& B & 279 & $1.17(\mathrm{~b})$ & 1.45 & \\
& C & 272 & $1.01(\mathrm{~b})$ & 1.28 & \\
& Total & 825 & 1.22 & 1.46 & \\
S2 & A & 274 & $0.83(\mathrm{a})$ & 1.20 & $0.001^{* *}$ \\
& B & 279 & $0.84(\mathrm{a})$ & 1.30 & \\
& C & 272 & $1.22(\mathrm{~b})$ & 1.67 & \\
& Total & 825 & 0.96 & 1.41 & \\
\hline
\end{tabular}

A: Non-Medical, B: Para-Medical, C: Medical. S0: Healthy score, S1: Bleeding score, S2: Calculus score. Test used ANOVA and Scheffe test. a, b: The mean values with different alphabets differ significantly. ${ }^{* *}: P \leq 0.001$.

The mean number of sextants with calculus was significantly higher for the Medical category (1.22 \pm 1.67 ) compared to the Non-Medical and Paramedical categories. There was no statistically significant difference between the mean number of sextants with calculus for the students in the NonMedical and Para-Medical categories.

The percentage of students with healthy periodontium was $36.8 \%(n=304)$, with bleeding on probing was $19.4 \%(n=160)$ and with calculus was $43.8 \%$ ( $n=361)$ (Data not shown).

As shown in Table 6, there was no statistically significant difference in the mean number of sextants with score healthy periodontium, bleeding and calculus in males and females.

\section{Dental caries status}

As shown in Table 5, the decayed teeth (DT) score was a major component in the DMFT score and the mean number of decayed teeth was highest for the Non-Medical category $(1.41 \pm 1.68)$ and was lowest for the Para-Medical category $(1.12 \pm$ 1.68).

The mean number of filled teeth was highest for the Para-Medical category $(1.14 \pm 0.56)$ and was lowest for the Medical category $(0.09 \pm 0.32)$.

The mean number of teeth missing due to caries was highest for the Para-Medical category $(0.04 \pm$ 0.24 ) and was lowest for the Medical category $(0.02 \pm 0.15)$.

The mean DMFT score was highest for the Non-Medical category $(1.53 \pm 1.75)$ and lowest for the Medical category $(1.28 \pm 1.90)$.

The total percentage of students with dental caries was $46.2 \%$, with filled teeth was only $7.2 \%$, with teeth missing due to caries was $2.5 \%$ and with DMF score more than 4 was $14.1 \%$ in all (Data not shown).

The mean number of decayed teeth was significantly higher in male students compared to female students whereas there was no statistically significant difference in the mean number of filled teeth, teeth missing due to caries and the DMFT score in both the sexes, as demonstrated in Table 6 .

Table 5 Assessment and comparison of mean number of decayed teeth, teeth missing due to caries, filled teeth and mean DMFT scores among the professional students

\begin{tabular}{lllllc}
\hline & Group & No. & Mean & SD & $P$ \\
\hline DT & A & 274 & 1.41 & 1.68 & 0.110 \\
& B & 279 & 1.12 & 1.68 & \\
& C & 272 & 1.17 & 1.85 & \\
& Total & 825 & 1.23 & 1.74 & \\
MT & A & 274 & 0.03 & 0.19 & 0.585 \\
& B & 279 & 0.04 & 0.24 & \\
& C & 272 & 0.02 & 0.15 & \\
& Total & 825 & 0.03 & 0.20 & \\
& A & 274 & 0.09 & 0.39 & 0.274 \\
& B & 279 & 0.14 & 0.56 & \\
& C & 272 & 0.09 & 0.32 & \\
& Total & 825 & 0.11 & 0.44 & \\
DMFT & A & 274 & 1.53 & 1.75 & 0.212 \\
& B & 279 & 1.30 & 1.85 & \\
& C & 272 & 1.28 & 1.90 & \\
& Total & 825 & 1.37 & 1.84 & \\
\hline
\end{tabular}

A: Non-Medical, B: Para-Medical, C: Medical. DT: Decayed teeth, MT: Teeth missing due to caries, FT: Filled teeth, DMFT: DT+MT+FT. Test used - ANOVA.

\section{Relationship of periodontal and dental caries status with knowledge, attitude and behavior}

As shown in Table 7, the oral health behavior of the students has a linear relationship with the attitude of the students depicting the influence of 
Table 6 Assessment and comparison of mean percentage knowledge, attitude and behavior scores, mean number of sextants with different CPI scores and mean number of decayed teeth, teeth missing due to caries, filled teeth and mean DMFT scores by gender

\begin{tabular}{|c|c|c|c|c|c|c|c|c|c|c|c|c|c|}
\hline \multirow[t]{2}{*}{ Sex } & \multirow[t]{2}{*}{ No. } & & \multicolumn{3}{|c|}{ Knowledge, attitude \& behavior scores } & & \multicolumn{3}{|c|}{ CPI Scores } & & \multicolumn{3}{|c|}{ Dental caries scores } \\
\hline & & & Mean & SD & $P$ & & Mean & SD & $P$ & & Mean & SD & $P$ \\
\hline M & 577 & KS & 51.53 & 15.28 & $0.000^{\star *}$ & so & 3.77 & 2.18 & 0.41 & DT & 1.32 & 1.79 & $0.023^{*}$ \\
\hline $\mathrm{F}$ & 248 & & 57.26 & 13.71 & & & 3.91 & 2.28 & & & 1.02 & 1.60 & \\
\hline $\mathrm{M}$ & 577 & AS & 72.65 & 20.96 & $0.000^{\star *}$ & S1 & 1.24 & 1.44 & 0.48 & MT & 0.03 & 0.18 & 0.340 \\
\hline $\mathrm{F}$ & 248 & & 80.38 & 18.25 & & & 1.17 & 1.51 & & & 0.04 & 0.23 & \\
\hline $\mathrm{M}$ & 577 & BS & 57.35 & 18.89 & $0.000^{* *}$ & S2 & 0.98 & 1.38 & 0.60 & FT & 0.10 & 0.40 & 0.622 \\
\hline $\mathrm{F}$ & 248 & & 63.13 & 17.88 & & & 0.92 & 1.49 & & & 0.12 & 0.52 & \\
\hline $\mathrm{M}$ & & & & & & & & & & DMFT & 1.45 & 1.88 & 0.054 \\
\hline $\mathrm{F}$ & & & & & & & & & & & 1.18 & 1.74 & \\
\hline
\end{tabular}

KS: Knowledge score, AS: Attitude score, BS: Behavior score. S0: Sound score, S1: Bleeding score, S2: Calculus score. DT: Decayed teeth, MT: Teeth missing due to caries, FT: Filled teeth, DMFT: DT+MT+FT. Test used - Student T-test. *: $P \leq 0.05, * *: P \leq 0.001$.

attitude, beliefs in molding the behavior, but no significant linear relation with the knowledge which shows that knowledge was not enough to influence the behavior.

Table 7 Regression analysis: for oral health behavior on oral health knowledge and attitude

\begin{tabular}{|c|c|c|c|}
\hline & Df & Mean square & $P$ \\
\hline Regression & 2 & 21236.585 & $0.000^{* *}$ \\
\hline Residual & 822 & 301.350 & \\
\hline Total & 824 & & \\
\hline \multicolumn{4}{|c|}{$2=0.15$. } \\
\hline & Coefficients & Std. error & $P$ \\
\hline Intercept & 30.272 & 2.731 & $0.000^{* *}$ \\
\hline KS & 0.084 & 0.043 & 0.051 \\
\hline AS & 0.325 & 0.031 & $0.000^{*}$ \\
\hline
\end{tabular}

Dependent variable: BS. KS: Knowledge score, AS: Attitude score, BS: Behavior score. *: $P \leq 0.05, * *: P \leq 0.001$.

Table 8 shows the mean percentage knowledge, attitude and behavior scores of the students with different periodontal status (CPI scores - healthy, bleeding and calculus).

There was no significant difference in the mean percentage knowledge scores of the students with CPI scores - healthy, bleeding and calculus, whereas the students with CPI score 1 (bleeding) and CPI score 2 (calculus) showed a statistically significant difference in the mean percentage attitude and behavior scores. The students with CPI score 2 showed a significantly lower mean percentage attitude scores compared to the students with CPI score 0 . The mean percentage behavior score was lowest for students with CPI score $2(55.28 \pm 18.63)$ and showed a statistically significant difference on comparison with students having CPI score 0 and CPI score 1.

As demonstrated in Table 9, the regression analysis for mean DMFT score on knowledge, attitude and behavior in all the students showed that the mean DMFT score of the students was dependent on the oral health behavior depicting the influence of oral hygiene practice, but no

Table 8 The mean percentage knowledge, attitude and behavior scores of the students with mean number of sextants having different CPI scores

\begin{tabular}{clclcc}
\hline & & No. & \multicolumn{1}{c}{ Mean } & SD & $P$ \\
\hline KS & S0 & 304 & 51.63 & 14.83 & 0.062 \\
& S1 & 159 & 54.40 & 15.88 & \\
& S2 & 360 & 54.08 & 14.80 & \\
& Total & 823 & 53.24 & 15.06 & \\
AS & S0 & 304 & $78.29(a)$ & 19.15 & $0.000^{\star *}$ \\
& S1 & 159 & 76.21 & 21.42 & \\
& S2 & 360 & $71.57(b)$ & 20.72 & \\
& Total & 823 & 74.95 & 20.50 & \\
BS & S0 & 304 & $63.02(a)$ & 17.74 & $0.000^{* *}$ \\
& S1 & 159 & $59.88(a)$ & 19.30 & \\
& S2 & 360 & $55.28(b)$ & 18.63 & \\
& Total & 823 & 59.03 & 18.74 & \\
\hline
\end{tabular}

KS: Knowledge score, AS: Attitude score, BS: Behavior score. S0: Sound score, S1: Bleeding score, S2: Calculus score. Test used - ANOVA and Scheffe test. a, b: The mean values with different alphabets differ significantly. ${ }^{* *}: P \leq 0.001$.

Int J Oral Sci, 1(4): 196-206, 2009 - 201 - 
Table 9 Regression analysis: for total DMFT on oral health knowledge, attitude and behavior

\begin{tabular}{|c|c|c|c|}
\hline & Df & Mean square & $P$ \\
\hline Regression & 3 & 9.370 & $0.040^{*}$ \\
\hline Residual & 821 & 3.359 & \\
\hline Total & 824 & & \\
\hline \multicolumn{4}{|c|}{$=0.010$. } \\
\hline & Coefficients & Std. error & $P$ \\
\hline Intercept & 1.351 & 0.309 & $0.000^{* *}$ \\
\hline KS & 0.008 & 0.005 & 0.090 \\
\hline AS & 0.002 & 0.004 & 0.592 \\
\hline BS & -0.009 & 0.004 & $0.015^{*}$ \\
\hline
\end{tabular}

Dependent variable: DMFT. KS: Knowledge score, AS: Attitude score, BS: Behavior score. *: $P \leq 0.05, * *: P \leq 0.001$.

significant relationship with the knowledge and attitude of the students.

\section{Discussion}

This study presented a comprehensive overview of oral health knowledge, attitude, behavior, periodontal status and the dental caries status of professional college students in Udaipur city, Rajasthan. Though the students showed a positive attitude, certain "preventive behaviors" such as twice daily brushing, dental floss use, reduction in sweet consumption etc. were not adequate, which reflects a low level of knowledge among the students.

As was expected, the Medical students had the highest knowledge, attitude and behavior scores. The oral health knowledge, attitude and behavior was significantly higher in the Medical and ParaMedical students compared to the Non-Medical students, perhaps because it is an important content in their professional education, and they need this knowledge to educate patients and community when they start working in health care system. As being the health care personnel their attitude not only affects their own oral health behavior but also potentially influence the health behavior of the patients and community.

In agreement with the results of Polychronopoulou et al. (2002), in general females students showed significantly higher oral health knowledge, attitude and behavior scores compared to the male students. In agreement with the results of some previous studies (Kawamura et al., 1993; Lim et al.,
1994; Schwarz, 1994; Fukai et al., 1995; Ostberg et al., 1999; Kawamura et al., 1999; Al-Omari et al., 2005; Pellizzer et al., 2007), the present study proved that females generally have better oral health behavior than males. Past discussions of similar findings have suggested that they result both from a greater interest in health among women and from greater social pressure on women to be physically attractive (Rakowski et al., 1990; Ronis et al., 1993; Langlie, 1977). In contrast to the results of the present study there was no gender difference in the knowledge, attitude and behavior of the senior Iranian dental students in a study by Khami et al. (2007).

Previous studies have shown that mass media, dental professionals, and dental literature are the main sources of oral health information (Paik et al., 1994). In the present study the sources of information were magazines/books, Physician's office/ health clinics, family members, Radio/television, dental professionals, news papers and peers in descending order.

In the present study, the mean number of healthy sextants per person was found to be higher than that found among Jordanian adolescents (Taani, 1995), among the Iranian adolescents (Sanei et al., 2005) and found in a study among 12-16 year old children in Banglore district (Manjunath et al., 2007).

In the present study, the mean number of sextants with bleeding on probing, with calculus and shallow and deep pockets (none), were less compared to those found in the Jordanian adolescents (Taani, 1995 ) and 12-16 year old children in a study by Manjunath et al. (2007).

The percentage of students with healthy periodontium, found in the present study, was less compared to the Jordanian adolescents (Taani, 1995), the fourth and fifth year dentistry students in a study by Stypułkowska et al. (2003), the 20-29 year old adults in northern Jordan (El-Qaderi, 2004), or the undergraduate dental students in a study by Mathur et al. (2008).

In the present study, the percentage of students with healthy periodontium was high, compared to the urban employees in Japan (Kawamura et al., 1993), the children in a study by Christensen et al. (2003), the Iranian adolescents (Saanei et al., 2005), and the 12-16 year old children in a study by 
Manjunath et al. (2008).

In the present study the percentage of CPI score for bleeding, calculus and pockets were lower compared to the Iranian adolescents (Sanei et al., 2005), and lower than in the undergraduate dental students in a study by Mathur et al. (2008).

The percentage of CPI score for bleeding and calculus, found in the present study was more compared to the fourth and final year dentistry students in a study by Stypułkowska et al., in whom the percentage was lower for both bleeding and calculus (Stypułkowska et al., 2003).

The percentage of students with calculus was found to be significantly high (43.8\%) in the present study. In another study (Peng et al., 1997), about $65 \%$ of the urban Chinese children had CPITN maximum score 2 (gingival bleeding and calculus).

In the present study, shallow and deep pockets were not found in any of the subjects unlike those found among urban employees in Japan (Kawamura et al., 1993) and the Jordanian adolescents (Taani, 1995).

In contradiction to the results of some previous studies (Ashraf-Sadat Sanei and Alireza NikbakhtNasrabadi, 2005; US department of Health and Human services, National centre for health statistics, 1997) no statistically significant difference was found in the mean number of sextants with healthy, bleeding and calculus score; for males and females.

The mean DMFT score per person, found in the present study was lower compared to the fourth and fifth year dentistry students in a study by Stypułkowska et al. (2003), the children in a study by Christensen et al. (2003), the young Israeli adults (Levin et al., 2004), the adolescent's in two Hungarian Cities (Madlena et al., 2000), whereas the mean DMFT score was found to be higher compared to the urban Chinese children (Peng et al., 1997) and the school children in a study by David et al. (2005).

In agreement with the results of some previous studies (David et al., 2005; Peng et al., 1997), in the present study the DT score dominated the DMFT score among the students, indicating a high rate of unmet treatment needs.

In agreement with the results of a recent study (Mathur et al., 2008) among the undergraduate dental students, in the present study the DT com- ponent of DMFT score was significantly higher in female students compared to their male colleagues and the mean DMFT score did not show a statistically significant difference among them. This finding is in contradiction to previous surveys in which females have usually demonstrated higher DMF scores than males of the same age (Public Health Service, National Centre for Health Statistics, 1971; US Public Health Service, National Institute of Dental Research, 1987).

Results of the present study showed a statistically significant linear relationship of oral health behavior with the attitude of the students depicting the influence of attitude, beliefs in molding the behavior, but no significant linear relation with the oral health knowledge. This finding was similar to that of Freeman et al.(1993) and Astrom (2002), who stated that though oral health knowledge is considered to be an essential pre-requisite for health related behavior but only weak association seems to exist between knowledge and behavior.

The result that the periodontal and dental caries status was independent on oral health knowledge, was in agreement with the results of a study by Kawamura et al. (1993).

In the present study, the students with healthy periodontal status had significantly higher attitude and oral health behavior than students with either bleeding or calculus. The regression analysis showed that the mean DMFT scores were dependent on the oral health behavior of the students depicting the influence of oral hygiene practices in the dental caries status.

These results are in agreement with the findings from previous research documenting a positive association between preventive oral behaviors and oral health status (Tedesco et al., 1992; Tedesco et al., 1993; Lang et al., 1994; Lang et al., 1995; Boehmer et al., 1999; Levin et al., 2004; Michiko et al., 2005; Spalj et al., 2006). The limitation of the present study is that the results related to oral health knowledge, attitude and behavior rely on self reported data, the rates of oral health behavior may be biased through over and under reporting due to social desirability.

In summary, these results indicate that the "oral health knowledge" was not enough to influence the "oral health behavior", but the behavior was dependent on the "attitude" of the students. Results also 
indicate that oral health attitude and behavior were the predictors of periodontal and dental caries status of the students, but the oral health knowledge did not show a positive correlation with the oral health status. This means that a positive attitude and adherence to good oral hygiene behaviors leads to better overall oral health through reduction in dental cries and periodontal disease.

\section{Conclusion}

It may be concluded that the oral health knowledge among the professional college students was considerably lower than what would be expected of these groups, which had higher literacy levels, but they showed a positive attitude towards oral health and dental professionals. The oral health behavior of the students was dependent on attitude but did not show a linear relationship with the oral health knowledge.

The results indicate that the oral health knowledge was not enough to influence the oral health status, but attitude and oral health behavior had an influence on the dental caries and periodontal status of the students.

So oral health awareness among these students should be increased for which the health professionals working collectively need to support the development of a "sound strategy".

Oral health education and motivation of people to adopt healthy behaviors would play a most important role in order to control oral disease. The oral health educational and motivational needs described in this study exist in many developing countries. While this study examined the oral health knowledge, attitude and behavior; the periodontal and dental caries status of professional students, more detailed studies probing these issues in depth are needed in different target populations. There is scarcity of data regarding oral health care attitudes in Indian. To develop a sound strategy for improving dental and oral health of Indian population, a more representative data base should be made available. For this, additional studies are needed using reliable and indigenously developed attitude scales.

\section{Acknowledgements}

The authors wish to thank Principal, Pacific Dental College and Hospital Debari, Udaipur, and Dr. Jagat Sharda, Associate professor, Department of orthodontics, Pacific Dental College and Hospital Debari, Udaipur, Rajasthan for all the support and help rendered.

\section{References}

Al-Omari QD, Hamasha AA (2005). Gender-specific oral health attitudes and behavior among dental students in Jordan. J Contemp Dent Pract, 6(1): 107-114.

Mathur A, Jain M, Kumar S, Dagli RJ, Duraiswamy P, Kulkarni S (2008). Oral health status of undergraduate dental students pursuing their career at a dental institution in India. Chin J Dent Res, 11(1): 47-51.

Sanei AS, Nikbakht-Nasrabadi A (2005). Periodontal health status and treatment needs in Iranian adolescent population. Arch Iranian Med, 8(4): 290-294.

Astrøm A (2002). Comparative risk judgment for oral health hazards among Norwegian adults: a cross-sectional study. BMC Oral Health, 2(1): 3.

Barmes DE (1999). A global view of oral diseases: today and tomorrow. Community Dent Oral Epidemiol, 27 (1): $2-7$.

Berndt TJ (1982). The features and effects of friendship in early adolescence. Child Dev, 53(6): 1445-1460.

Block LE, Freed JR (2003). Chapter 1//Gluck GM, Morganstein WM. Jong's Community Dental Health, $5^{\text {th }}$ ed. Missouri: Mosby, An Imprint of Elsevier Science.

Boehmer U, Kressin NR, Spiro A 3rd (1999). Preventive dental behaviors and their association with oral health status in older white men. J Dent Res, 78(4): 869-877.

Chen MS (1986). Children's preventive dental behavior in relation to their mother's socioeconomic status, health beliefs, and dental behaviors. ASDC J Dent Child, 53(2): 105-109.

Christensen LB, Petersen PE, Bhambal A (2003). Oral health and oral health behavior among 11-13-year-olds in Bhopal, India. Community Dent Health, 20(3): 153-158.

David J, Wang NJ, Astrom AN, Kuriokose S (2005). Dental caries and associated factors in 12-year-old schoolchildren in Thiruvananthapuram, Kerala, India. Int J Paediatrc Dent, 15(6): 420-428.

El-Qaderi SS, Quteish Ta'ani D (2004). Assessment of periodontal knowledge and periodontal status of an 
adult population In Jordan. Int J Dent Hyg, 2(3): 132136.

Freeman R, Maizels J, Wyllie M, Sheiham A (1993). The relationship between health related knowledge, attitude and dental health behaviors in 14-16 years old adolescents. Community Dent Health, 10(4): 397-404.

Friedman LA, Mackler IG, Hoggard GJ, French CI (1976). A comparison of perceived and actual dental needs of a selected group of children in Texas. Community Dent Oral Epidemiol, 4 (3): 89-93.

Fukai K, Takaesu Y, Maki Y (1999). Gender differences in oral health behavior and general health habits in an adult population. Bull Tokyo Dent Coll, 40(4): 187-93.

Hagquist C, Starrin B (1997). Health education in schoolsfrom information to empowerment models. Health Promot Int, 12(3): 225-232.

Honkala E (1995). Oral health promotion with children and adolescents//Cohen LK, Gift HC. Disease prevention and oral health promotion. Cophenhagen: Munsksgaard: 169-187.

Hopkins N (1994). Peer group processes and adolescent health-related behavior: more than 'peer group pressure'? J Community Appl Sociol Psychol, 4(5): 329-345.

Institute of Medicine Committee for the Study of the Future Public Health, Division of Health Care Services (1998). A vision of public health in America: an attainable ideal. In the future of public health. Washington DC: National Academy Press.

Kawamura M, Sasahara H, Kawabata K, Iwamoto Y, Konishi K, Wright FA (1993). Relationship between CPITN and oral health behavior in Japanese adults. Aust Dent J, 38(5): 381-388.

Kawamura M, Wright FAC, Sasahara H, Yamasaki Y, Suh S, Iwamoto Y (1999). An analytical study on gender differences in self-reported oral health care and problems of Japanese employees. J Occup Health, 41(2): 104-111.

Khami MR, Virtanem JI, Jafarian M, Murtomaa H (2007). Prevention-oriented practice of Iranian senior dental students. Eur J Dent Educ, 11(1): 48-53.

Lang WP, Farghaly MM, Ronis DL (1994). The relationship of preventive dental behaviors to periodontal health status. J Clin Periodontol, 21(3): 194-198.

Lang WP, Ronis D1, Farghaly MM (1995). Preventive behaviors as correlates of periodontal health status. $J$ Public Health Dent, 55(1): 10-17.

Langlie JK (1977). Social networks, health beliefs and preventive health behavior. J Health Soc Behav, 18(3): 244-260.

Levin L, Shenkman A (2004). The relationship between dental caries status and oral health attitudes and behavior in young Israeli adults. $J$ Dent Educ, 68(11): 1185-1191.

Levine RS, Stillman-Lowe C (2001). The scientific basis of dental health education. Part one. London: Health Development Agency.

Lim SP, Schwarz E, Lo ECM (1994). Chinese health beliefs and oral health practices among the middle-aged and elderly in Hong Kong. Community Dent Oral Epidemiol, 22(5): 364-368.

Madlena M, Gabris K, Banoczy J, Marton S, Keszthelyi G (2000). Correlation between adolescent's caries prevalence and caries related factors in two Hungarian cities. Acta Stomatol Croat, 35(3): 313-317.

Maxwell KA (2002). Friends: the role of peer influence across adolescent risk behaviors. J Youth Adolesc, 31(4): 267-277.

McCaul KD, Glasgow RE, Gustafson C (1985). Predicting levels of preventive dental behaviors. J Am Dent Assoc, 111(4): 601-605.

Michiko T (2005). Relationship between oral health behavior and oral health status in adults. $J$ Dent Health, 55(3): 173-185.

Oliveria ER, Narendran S, Williamson D (2000). Oral health knowledge, attitudes and preventive practices of third grade school children. Pediatric Dent, 22: 395-400.

Ostberg AL, Halling A, Lindblad U (1999). Gender differences in knowledge, attitude, behavior and perceived oral health among adolescents. Acta Odontol Scand, 57(4): 231-236.

Paik DI, Monn HS, Horowitz AM, Gitt HC, Jeong KL, Suh SS (1994). Knowledge of oral practices related to caries prevention among Koreans. J Public Health Dent, 54(4): 205-210.

Park K (2005). Park's textbook of preventive and social medicine. $18^{\text {th }}$ ed. Jabalpur (India): M/s Banarsidas Bhanot Publishers.

Pellizzer C, Pejda S, Špalj S, Plančak D (2007). Unrealistic optimism and Demographic influence on oral health-related behavior and perception in Adolescents in Croatia. Acta Stomatol Croat, 41(3): 205-215.

Peng B, Petersen PE, Fan MW, Tai BJ (1997). Oral health status and oral health behavior of 12-year-old urban school children in the People's Republic of China. Community Dent Health, 14(4): 238-244.

Petersen AC (1988). Adolescent development. In: Rosenzweig MR ed. Annual review of psychology. Vol 39. Palo Alto, CA: Annual Reviews. pp. 583-607.

Polychronopoulou A, Kawamura M, Athanasouli T (2002). Oral self-care behavior among dental school students in Greece. J Oral Sci, 44(2): 73-78.

Puranik MP, Hiremath SS (2007). Periodontal treatment needs in 12-16 year old children in Banglore district (A 
comparative study). J Indian Associ Public Health Dent, (9): 18-26.

Rakowski W, Assaf AR, Lefebvre RC, Lasater TM, Niknian M, Carleton RA (1990). Information-seeking about health in a community sample of adults: Correlates and associations with other health related practices. Health Educ Q, 17(4): 379-393.

Ronis DL, Lang WP, Farghaly MM, Passoe E (1993). Toothbrushing, flossing, and preventive dental visits by Detroit-area residents in relation to demographic and socioeconomic factors. J Public Health Dent, 53(3): 138-145.

Schwarz E, Lo EC (1994). Dental health knowledge and attitude among middle age and elderly in Hong Kong. Community Dent Oral Epidemiol, 22(5): 358-363.

Sheiham A, Watt RG (2000). The common risk factor approach; a rational basis for promoting oral health. Community Dent Oral Epidemiol, 28(6): 399-406.

Spalj S, Panacak D, Juric H, Srdjak S (2006). Knowledge, motivation and habits in oral hygiene in relation to oral health of young people in Croatia. J Clin Periodontol, 33 (Suppl 7): S137.

Stypułkowska J, Łyszczarz R, Wichliński J, Pawłowska K, Solska-Kuczerek A (2003). Oral health state in dentistry students of Medical College, Jagiellonian University in Cracow. Przegl Lek, 60(Suppl 6): 122-125.

Taani Q (1995). The periodontal status of Jordanian adolescents measured by CPITN. Int Dent J, 45(6): $382-385$
Tedesco LA, Keffer MA, Devis EL, Christersson LA (1992). Effect of social cognitive intervention on oral health status, behavior reports and cognitions. $J$ Periodontol, 63(7): 567-575.

Tedesco LA, Keffer MA, Devis EL, Christersson LA (1993). Self-efficiency of reasoned action: predicting oral health status and behavior at one, three and six month intervals. Psychol Health, 8(2/3): 105-121.

US department of Health and Human services, National centre for health statistics. Third National Health and Nutrition examination survey, 1988-94. Public US data file No. 7-0627. Hyattsville MD: CDC 1997.

US Public Health Service, National Centre for Health Statistics (1971). Decayed, missing and filled teeth among children. United States. DHEW publication No. (HSM) 72-1003, series 11 No. 106. Washington DC: Government printing office.

US Public Health Service, National Institute of Dental Research. (1987). Oral health of United States adults, national findings. NIH publication No. 87-2868. Washington DC: Government printing office.

WHO (1997). Oral Health Surveys - Basic Methods. $4^{\text {th }}$ Ed. Geneva: World Health Organization.

Wright FA (1982). Children's perception of vulnerability to illness and dental disease. Community Dent Oral Epidemiol, 10(1): 29-32.

Zhu L, Petersen PE, Wang HY, Bian JY, Zhang BX (2003). Oral health knowledge, attitudes and behavior of children and adolescents in China. Int Dent J, 53(5): 289-298.

*Corresponding authors: Archana J. Sharda

Address: Department of Preventive and Community Dentistry, Pacific Dental College \& Hospital, Debari, Udaipur 313001, Rajasthan, India

Tel: $919828568810 \quad$ E-mail: shardaarchana@yahoo.com 